\title{
The Hybrid Journalism That We Do Not Recognize (Anymore)
}

\author{
Sergio Splendore ${ }^{1, *(\mathbb{D})}$ and Margherita Brambilla ${ }^{2}$ (D) \\ 1 Department of Social and Political Sciences, University of Milan, 20122 Milan, Italy \\ 2 Independent Researcher, 20122 Milan, Italy; mbrambilla94@gmail.com \\ * Correspondence: sergio.splendore@unimi.it
}

\section{check for}

updates

Citation: Splendore, Sergio, and Margherita Brambilla. 2021. The Hybrid Journalism That We Do Not Recognize (Anymore). Journalism and Media 2: 51-61. https://doi.org/ 10.3390/journalmedia2010004

Received: 14 November 2020 Accepted: 9 February 2021

Published: 20 February 2021

Publisher's Note: MDPI stays neutral with regard to jurisdictional claims in published maps and institutional affiliations.

\begin{abstract}
In the past 20 years the world of journalism has been swept by a wave of structural, institutional and technological changes that have shaped the journalism that we experience today. Following conceptualization of hybrid media, the term 'hybrid journalism' has been used to define what journalism has become. Many scholars have subjected this label to scrutiny; they consider hybridity to be a vague term that requires a more precise conceptualization. In this paper, we propose that what to date has been called 'hybrid journalism' has moved from the periphery to the center of the field. Adopting a communicative ecology perspective, we highlight that the changes due to technologies, which too often are regarded as merely disrupting the journalistic field, have now become established and are accepted as core components of the work of journalists today. This reconstruction work is mainly discursive and is explained by considering journalism as a discursive institution. We then explain the implications of studying journalism with acknowledgement that hybrid forms of journalism that are central in the field are hybrid.
\end{abstract}

Keywords: hybrid journalism; boundary work; media ecology; post-industrial journalism; journalism studies

\section{Introduction}

This is not an article about how journalism has been changing. This is an article about how journalism has changed. Although we do not apply a historical perspective, when we affirm that journalism has (irremediably and dramatically) changed, we have in mind a time-span of 20 years. What was recognized and identified as journalism 20 years ago still exists, but it is only a part of what journalism actually is in the contemporary media ecology. Twenty years is not a conventional time period. It is the period that has elapsed since journalism studies established themselves as an autonomous research field. Additionally, at the same time, it is the period in which journalism studies have been able to study and analyze, and not rarely overemphasize, these changes. It is also the time period in which the world of journalism (and not only) has witnessed the most rapid technological changes of modernity. Historically, journalism underwent numerous changes also in previous centuries, but in recent decades the pace of these changes has been the most impressive (Deuze and Witschge 2020; Livingstone 2011). As Zelizer (2019) writes: “Digital technology has introduced marked differences in journalistic style, information-gathering, sourcing, analysis, distribution and financing that have led in turn to new presentational formats [...] make today's news feel more proximate and personalized, usable and interactive than ever before." (Zelizer 2019, p. 344).

One way to overcome reductionism and maintain the complexity of today's journalism is to adopt the media ecological lens. This means considering the study of the technological environment in which journalism operates not as additive, but as ecological. When a new technology is used in journalism, it does not supplant the existing technologies but interacts with them. In this way, our reasoning may convey the connections between journalism in its various forms, on the one hand, and media technologies on the other. The media ecology approach is suitable for describing interconnections and dynamic changes; it is 
able to investigate the relation between journalism and technology from an evolutionary perspective, while also exploring the coevolution of multiple media, news formats and discourses (see Scolari 2012).

Media ecology is already the subject of a well-defined-and extensive-literature that comprises nuanced, juxtaposed and contrasting approaches. In this article, we derive the term 'media ecology' from a stream of literature that since Altheide's definition (Altheide 2013) is usually termed 'communicative ecology' (see also Treré and Mattoni 2016). Adopting a holistic approach therefore means considering media ecology through at least two other layers beyond technology: modes of organization, and discursive content. The way in which we understand journalism must consider all three of these aspects and their interactions. The use of Twitter (technology) cannot be properly understood if it is not related to tweet contents (and the discourses that they generate also beyond news items) and the ways in which the news-making process adapts to the use of the former (technology) and the creation of the latter (content and discourse).

Technology as a whole (technology and devices, but also platforms, social media, the functioning of algorithms, and so forth) is often identified as the predominant cause of the change in journalism, both in the production of news items and in their reception by the audience. To provide a notable—but certainly not exhaustive-example, Google and Facebook algorithms determine which news readers receive their platforms (Gillespie et al. 2014). Technology also determines how news outlets select items of news to be published online according to the potential 'likeability' or ranking that they may receive from a search engine. WhatsApp, users' comments, Twitter, TikTok, and many other digital tools (and their affordances) have numerous important implications for journalists. Nevertheless, the communicative ecology approach forces us to analyze those technological implications in their relations with socio-organizational aspects of journalism and discursive aspects.

In regard to organizational issues, the easiest way to explain them is to cite examples. How has journalism changed what it takes for granted? How has it adapted its organization to meet those changes? For years, journalism took it for granted that speed and brevity were the measures of digital journalism (on many occasions this is still true). This shaped organizations able to cover the news promptly. The introduction (or more extensive use) of shifts in journalistic work is an example of this. Over time it has been discovered that slowness (Le Masurier 2016) or length (Hiippala 2017) may also be welcomed by readers. Obviously, many newsrooms have changed to meet these new convictions as well, convictions that became a new "taken for granted". Organizational change in newsrooms has in fact been a recurrent topic in the past two decades (see Sehl et al. 2019 and Usher 2014 among many other works).

As said, when a media ecology approach is adopted, there is a third layer to consider: the discursive content that journalism creates. This has an important role in determining from an ecology perspective how journalism has changed. In journalism, discursive content must be considered along three dimensions. First, the content that journalism produces. What is news? What do journalism consider to be news? Additionally, what do citizens consider to be news? Second, what formats do journalists use to shape news? Whilst the concept of news may not have changed (and we slightly disagree with this point of view), the styles and formats in which news stories are presented have done so. The most traditional ways are now intertwined with an increasing number of different formats: data journalism, a long and interactive format, live tweeting, a photograph on Instagram, fact-checking platforms. There is a third way to conceive journalistic discursive production, and it is the most important one: journalism needs to be conceptualized as discursive construction and a struggle for authority to determine the locus of journalism in society (see Hanitzsch and Vos 2017). This third facet of journalistic discourse is acquiring increasing importance (see Koliska et al. 2020 as a striking example of the use of a discursive approach, but also Carlson 2016; Robinson and Anderson 2020). In this regard, the most challenging aspect is that most part of discursive struggle takes place within journalism itself, rather than outside it. To put it in Nielsen's thought-provoking terms (Nielsen 
2019), the discursive struggle is enacted between a rearguard and a vanguard where: "The rearguard thinks the problem is that the world has changed too much. The vanguard thinks the problem is that journalism hasn't changed enough" (Nielsen 2019).

These three layers cooperate, even without any intentional coordination, to limit and define both what journalism is today, and how it will change. Several research studies have investigated forms of hybrid journalism, doing so particularly through the socio-professional lens. Hybrid journalism is often considered to be a mere convergence between structurally different actors, like journalists and activists (Barnard 2016; Poell and Rajagopalan 2015), journalists and programmers (Hermida and Young 2017), producers and users of news (Harder et al. 2016; Papacharissi 2015), or as a convergence between reporting practices and uses of sources (Gil de Zúñiga et al. 2018; Delmastro and Splendore 2020). When the news is considered (using the above-described first and second ways to figure out the discursive content of journalism), some studies have explored hybridity among communication formats like fictive and factual forms of storytelling (Baym 2017), news and entertainment (Edgerly and Vraga 2019; Bailey 2018) or news and advertising/public relations (Erjavec 2004, 2005). These forms of hybrid journalism have been identified especially where the three layers discussed above are simultaneously involved. Therefore, a technological deterministic approach is not maintained; instead, to identify hybrid journalism, an interaction among those layers needs to be investigated.

Nevertheless, from our point of view the discursive level is the most important one (especially in its third form outlined above, the conceptualization of journalism as a discursive institution). As journalism has been interpreted and reinterpreted over time, it has been done so via a discursive interchange (see Hanitzsch and Vos 2017). This discourse is the one able to recompose fractures, changes, differences in a general understandingneither homogeneous nor unique-that defines the journalistic domain (Carlson and Lewis 2015). In addition, it is precisely there, at the discursive level, that the concept of 'hybrid journalism' asserts itself, finds a discursive reconstruction where hybrid elements are emphasized. Not rarely, its hybridity is also presented as component of journalistic authority (Carlson 2017). Journalism as a discursive institution establishes its place in society by accentuating its hybrid aspects, its ability to modify the organization to use a multiplicity of media and convey different kinds of knowledge and expertise. It stresses its ability to merge those media and those areas of expertise.

\section{The Hybrid Journalism That We Do Not Recognize (Any Longer)}

We are still talking about hybrid journalism, which is precisely what many scholarsthe ones we value most-suggest not to do. Hybridity in media often remains an allencompassing concept (Witschge et al. 2019) and everything appears to be there in an indistinguishable way. Moreover, the concept of hybridity implies that prior to the emergence of new 'hybrid' products, practices, and so on, there was something 'pure' -an assumption that is often criticized, especially in regard to journalism that is engaged in constant interactions with different actors. Finally, social sciences must make the effort to define the complexity of reality, rather than use vague concepts whose borders are difficult to identify. As Bowker and Star (2000) already stated 20 years ago, categorizing and classifying are fundamental social actions because they are important for human cognition and sense-making. Nevertheless, we disagree with the idea that hybridity is a concept too ambiguous to be fruitfully employed, and this article will seek to help the reader to precisely identify forms of hybrid journalism, convincing him/her that any other label is not appropriate to define them properly.

The hybrid media ecology underlines that the various forms of media and the actors that animate it are able to produce, distribute, and consume flows of news through different technologies and according to complex temporal and semantic structures. When the media have to account for these changes, they do so by employing discursive resources from different fields. For example, in some of its hybrid forms, journalism refers to the importance of statistics, or of engaging narrative forms, or of advanced marketing 
techniques. Journalism therefore resorts to those discursive contexts in order to justify its authority over the role of journalism in society. In other words, to determine what journalism actually is.

Chadwick (2013) propounded the most complete and comprehensive definition of hybrid media system. It encompasses and shapes the latest uses that have been made of the term 'hybrid media'. Affirming that Chadwick's (2013) perspective encompasses the others that have adopted - in different ways—-the expression 'hybrid media' means that, despite the existence of various uses of the term 'hybrid', Chadwick offers the only holistic overview of the concept. Many empirical investigations of hybridity processes have adopted a narrower approach that fits contexts well-defined in comparison to the one considered by Chadwick (2013). Chadwick adopted this holistic approach predominantly to disentangle the political communication flow.

According to Chadwick (2013), media should be regarded in terms of a dynamic and complex concept with many implications. Forms of hybridity arise precisely where loss of distinction and interdependence among actors entails an integration of cultural and institutional logics that were previously kept separate. The notion with which Chadwick (2013) mainly deals is 'media logic' discussed in Altheide and Snow's (1979) terms. Therefore, 'hybridity of media logics' means the hybridity of the process by which media organizations and practitioners determine how news material is categorized-how certain sources and items of news are picked rather than others and considered more or less prominent and/or worthy of coverage- and how the selection of social experience is performed in the media, including styles of communication formats. Decontextualizing and recontextualizing an event—a 'social experience' to use Chadwick's words-are the most typical activities of those who produce information. An event that could only be recounted through words, finds a multiplicity of forms of communication in contemporary journalism. These forms may be based on languages and methods distant from how journalism has always been understood. Technological change interacts with new organizational forms and different discursive styles. Beyond the first two levels of the discursive styles, news and formats, how journalism frames and justifies these changes becomes fundamental.

What differentiates this article's approach from Chadwick's framework, is that (1) it does not consider only the hybridity of technology, (2) it considers not only the hybridity of logics-meant in terms of implicit assumptions made by journalists, what they take for granted. It considers the hybridity of technology and logics also for their reciprocal and continuous relation with social models of organization and discursive content. This means that hybrid journalism occurs when a technological innovation is critical in changing socioprofessional modes of news production (practices and logic) and journalistic discourses (i.e., news, styles and discourses about the profession). Furthermore, it is also triggered when innovation means new socio-professional modes of news production (e.g., local media outlets run without any physical newsroom adopting modes of organization rooted in different production environments) or convincing new ways in which journalists present their work (e.g., open journalism is essentially discursive rather than technological, and it includes styles driven by marketing).

To provide an ideal-typical example that helps join the three layers considered here, one may cite uses of analytics in newsrooms (see Cherubini and Nielsen 2016). In general, to adopt analytics, newsrooms have to acquire and maintain a data-oriented expertise. Put very simply, a more traditional hybrid approach would analyze how the use of a data-driven attitude mixes with traditional journalistic attitudes. It would focus on the hybridized new cultural logic which arises from mixing different attitudes. By contrast, the conceptualization framework proposed here would analyze whether those tools generate different components of a given cultural logic and how they shape a new sense of implicitness. It would also analyze how they influence the modes of organization and the discursive content (not meant as just a communicative format of the news produced, but especially how journalism is conceptualized discursively due to those innovations and how that reconstruction affects their authority). 


\section{The Hybridity That Has Settled: Three Corollaries}

We recognize that the actors involved in journalism have somehow accepted that journalism has changed, and that some form of hybridity has become established in their everyday perception of what journalism is. The innovation in technology and the change in the socio-professional environment have somewhat melted into the journalism that is experienced today.

Regarding technological innovation, the issues are (i) what has happened as an adaptation (and resistance) to disruption (Eldridge and Broersma 2018); and (ii) whether the process of digitalization is a moment of reconfiguration. It is necessary explaining that what journalism has experienced has not been destructive, but creative. It is no coincidence that the younger generation is the one driving innovation (Broersma and Singer 2020), also in hybrid term.

Undoubtedly, this fertile technological ground has prompted more than one scholar to differentiate between journalism before and journalism after the process of digitalization since the first publications on the subject (Paterson and Domingo 2008). As early as 2011, Williams and Delli Carpini (2011) identified this critical disjuncture in the United States news system as due precisely to the digital boom. They affirmed that the media regime in place for the latter half of the 20th century had been dismantled and the contours of a new regime had yet to be formed. However, that was 2011. In the same year, the Nieman Journalism Lab started its, now decade-long, series of yearly predictions of changes in journalism (Predictions for Journalism 2011 2010). Some of these predictions were discarded, some came true. However, interestingly, there are common themes that are repeated year after year: disruption of economic models; data journalism; plurality of voices and the issue of gatekeeping and boundary work; the topic of integrity; how labor changes; and so forth. Not all, but most, of these themes regard keeping up with technological innovation. What one observes is a situation in which scholars, journalists, analysts, and observers have kept close track of the undeniable evolution that journalism has undergone in the past decade, and they have detected and predicted changes that, year after year, seemed less and less disruptive and more in line with what proposals that had been published the previous years. The change, though dynamic and flexible, has established itself as the core reality. Where Williams and Delli Carpini saw a disjuncture and a potential for creation, now something has settled into a hybrid form of journalismwith the characteristics mentioned in the previous paragraph-becomes more and more familiar every day. This point of view recalls what Karpf (2019) argued: that the pace of digital innovation is slowing down and that the suite of user-facing technologies has stabilized. Starting from a totally different background, Stross (1999) introduces the concept of 'hybridity cycle' in which forms that emerge as hybrids become stabilized and are seen as pure forms.

Technological innovation has brought many changes that journalism studies have been discussing for two decades (see Anderson et al. 2012; Peters and Broersma 2013; Carlson and Lewis 2015). We have already mentioned some of them (most discussed are how journalists first coped with the velocity of the digital ecology, and now also with its slow forms; but also, the possibility of direct interaction between journalist and reader). In this scenario, the mode of organization and the production of discourses play a vital role. Both have been crucial to the establishment of a hybrid form of journalism.

The mode of organization includes also how this change has interacted with labor, which is a fundamental change at both the media organization and individual levels. This issue prompted Deuze (2019) to wonder whether journalism can exist even beyond newsrooms (and his answer was "Yes, it can"). A decade ago, Compton and Benedetti (2010) noted that journalistic labor was going through a "tumultuous and chaotic storm". A series of culprits-" new technologies, shrinking audiences, 24-h news cycles, and intensified hyper-commercialization"-were shaping a new organization of labor and work in the profession that was generating a swathe of chaos in the form of lay-offs and cuts, but also 
a different conceptualization of the role and therefore of the work and requirements of the journalist.

News organizations are not looking only for journalists: they are also looking for data journalists, social media managers, graphic designers, podcast producers, engineers, and so on. Nowadays, to produce journalism a professional may also be something else. Additionally, this concerns not only working roles but also working conditions: "precarious working arrangements have come to determine newswork, even for those who in fact still enjoy a contracted job with a salary and benefits." (Deuze 2019). People who produce journalism —or at least some legitimately recognizable form of it—are today very different from those of the past in terms of their working conditions, settings, level of professionalization, and so on. Salaried journalists work alongside freelance journalists, dialogue with citizen journalists, and write pieces about news and information provided by people posting it online with no intention of doing journalism but, eventually, ending up in the process nevertheless.

As highlighted above, the third layer of conceptualization regards the content of journalism. From a discursive point of view, most journalistic cultures have yet to properly define and normalize this labor situation; however, the actors involved accept it as a factual reality. Witschge et al. (2019) underline how norms, and by extension, institutions "may play a crucial role in shaping how actors accept (or challenge) existing configurations of a network" (Witschge et al. 2019, p. 5).

It is necessary also to understand whether the concept of news has changed, and whether this influences a new, hybrid, mode production of news stories. However, most importantly, we need to assess whether these changes have become the new routine of journalism, what journalists take for granted, that is, the third layer: the discursive construction of journalism itself.

Whether hybridity as a concept has been overused, it is necessary to better conceptualize those stable, more static points that have become established in current journalistic practice. The argument is that those stable points are accepted and described as a new reality by the same people who do journalism today. Deuze (2019) highlights that there are strong coherences in the big picture, a sort of broad view of journalism that may yield a cohesive definition of what journalism is now. However, although there is no explicit consensus among journalists themselves about what journalism is today, it is undoubtedly true that they are doing journalism in a way that they previously did not. Those actors are producing news using an array of sources, tools and skills, with a completely new time-frame logic; and institutions and newsrooms are requesting these new ways to enact journalism (Chadwick 2013). They are discussing journalism by mostly enlarging the field and merging it with other items. If journalists are including their work within wider boundaries, it is not too bold to call it a 'hybrid'. Its definition might be fluctuating, it might be dynamic, but its actions are settled into something that many scholars, alongside professionals and readers, have come to call journalism.

There are three different corollaries to the conception of hybrid journalism as described so far.

1. Journalism studies have been talking for years about boundary-work (Carlson and Lewis 2015) and for decades about change in journalism (among others see Peters and Broersma 2013). Following this change, hybrid journalism is now the center of the field, and it is precisely for this reason that we do not recognize it anymore, because it is no longer the periphery. Hybrid journalism is not where the boundary-work actually is; rather, it is what is taken for granted. This does not mean that there is no longer boundary-work in journalism, far from it. It means that what in the field is discursively defined in hybrid terms has occupied a central position. If boundary-work determines what journalism is or is not, there is no question that hybrid journalism is Journalism. If boundary-work distinguishes which journalism discourse is more convincing than others, hybrid journalism is that compelling discourse. To cite Ryfe's (2012) book, which deals with the spread of online newsrooms in the American media 
system, hybrid journalism is the journalism that has survived (Ryfe 2012). Over the years, many scholars or meta-journalistic organizations have compiled lists of present or future innovations in journalism. Those forms of innovation have included technology, products, as well as kinds of organization. Commentators usually regarded each of them as disruptive-when they were pessimistic - or as innovative game changers-when they were looking for something that would revolutionize or at least reform journalism. Inspection of the many reflections on innovations in journalism shows that many of those innovations were discarded, forgotten, or set aside. They routinely failed (see Lenhard 2020). Many others are now simply journalism: they were "the future" and are now the backbone of journalism. Those innovations that today occupy an established position in journalism are hybrid forms of journalism: forms that create a coexistence among different cultural logics, different forms of organization and different discourses. Examples have already been cited: data-driven journalism, programmer journalism, open journalism, journalism that is produced within social media platforms, entrepreneurial journalism, WikiLeaks, and so forth. Those forms of journalism did not simply arise to remain in the field; they arose to occupy its central positions, to gain awards, to force the media industry to invest money, to hire people, to educate people in performing precisely those tasks. While in the past these forms of journalism were regarded as disruptive for a variety of reasons-because they were made by nonprofessionals; because they used nontraditional tools; because they produced items of news not in the form of articles or photography but of landing pages, interactive infographics, tweets, social media surveys and much more- they have been integrated into what today is regarded as journalistic practice, somewhat accepted and definitely hybrid.

2. So far, the emphasis has been on change. When scholars talk about the hybrid media system, and sometimes specifically about hybrid journalism, they depict a media environment in which traditional distinctions between concepts like 'online' and 'offline', 'producer' and 'audience', 'citizens' and 'journalists' are in question. The result is that the emphasis appears to be on change more than continuity and on difference more than similarity. The thesis of this article is exactly the opposite. In the contemporary media ecology environment, the most established forms of hybrid journalism represent continuity rather than change. What is changing is the most traditional part of the newsroom. Those forms are networked rather than being centralized, are often user-centered (and algorithmically managed) rather than being professionally controlled (Papacharissi 2015). They have been able to accomplish the shift from 'either/or' to 'both/and' (Mast et al. 2017); nevertheless, they now represent continuity rather than change.

3. The forms termed 'hybrid journalism' bring homogeneity rather than dissimilarly: procedures, practices, news content, even the discourse on the profession are increasingly standardized at global level. On the one hand, educational institutions are teaching those activities with programmes that are highly homogenized. Other activities are instead learnt by practitioners through an open and global dialogue that, in the end, homogenizes styles and practices (among others consider the leading role covered by the Tow Center of Digital Journalism, or the Center for Investigative Journalism, the streaming seminars provided by the Reuters Institute for the Study of Journalism or by the Hack/Hackers global team).

One practical example which corroborates these three corollaries to hybrid journalism is provided by inspection of job announcements from news organizations. In October 2020, a list of global journalism job announcements included an "Associate Director of Social Media" at Wired, a "podcast producer" at BuzzFeed News, a "Motion Graphics and Animation Editor" at The Guardian, a "Senior Software Engineer" and a "visual designer" at Bloomberg, a "video producer" at NPR, and "Marketing Designer" at the Atlantic: hybrid journalism as the center of the field, its continuity and its homogeneity around the globe. Scholars have accepted that journalism today is chaotic and messy and 
in "permanent flux". Therefore, scholars, journalists and users are more inclined to accept things like citizen journalism, or freelance/star journalism, or data journalism, and so on, as sort of a norm; none object to job openings like the ones seen above at BBC News, Wired, Bloomberg, or NPR: journalists have reached a point where they conceive journalism as something else from what it was before.

\section{Conclusions}

Having considered what is "the 'hybridity' that has settled", it is necessary to understand what the near future holds in store. Taking a closer-and perhaps a little more scrupulous-look at Nieman Lab's predictions for 2020 specifically, what we find is an interesting picture of what scholars, journalists, analysts, and observers thought would be the future of journalism approximately one year ago, and how they constantly produce it discursively (Predictions for Journalism 2020 2019). Some articles explore the relationship between the reader and journalism, suggesting ways for journalists to cater to evolving modes of consumption and, therefore, a new role of journalism in people's lives. Others explore recent technological innovations and trends, especially in regard to the role of audio journalism -in the form of podcasts, but also of new technological possibilities for the personalization of audio content to the single listener. Many others focus on the dichotomy between local newsmaking and national/international/global newsmaking, declaring one of the two options to be either dead or developing. Some articles delineate issues concerning paywalls and, in general, how to maintain an economic relationship with an audience. Borchardt (2019) writes about the youngest generation of journalists, one that has never truly been in the field but has done computer and desk work, and he predicts that they will be on the scene for the first time outside the office.

It is clear that what emerges from the various Nieman's Reports about the future of journalism - and not just the ones cited above - is a tendency to return to already beaten paths. On analyzing the Nieman Lab's predictions in the past decade, we found that many published articles presented emerging forms of journalism that, although recognizable as innovative and evolutive, can be ascribed to macro categories of change that were identified as changing aspects of journalism 10 years ago. This may be a sign that the evolution of hybrid journalism has been both accepted into daily practices and has not completely exhausted its innovative potential.

In the past 20 years, the journalistic world has undergone massive changes in what are identified as the base layers of the media ecology: technological innovation, social models of organization, and discursive content. Journalists and scholars have subjected these changes to scrutiny over the past decade. After Chadwick (2013) proposed the most comprehensive conceptualization of hybrid media, many saw his definition and label as outstanding descriptors of the evolution that journalism, as part of the hybrid media system, was undergoing.

Understandably, after at least a decade of studies on hybrid journalism, the label is starting to seem a little too inaccurate. Witschge et al. (2019) call for a greater effort to properly define the journalism of today. However, we believe that the concept of hybridity in journalism still offers opportunities and has a relevance that cannot be ignored.

This is because we believe that, fundamentally, what we are seeing now is not the destruction of an old world, but nor is it the birth of a completely new one. Before, hybrid journalism was the changes and the trends at the periphery of the field, the disruption that was forcing journalism to undertake serious boundary work. Now hybrid journalism is the core of the field: what was previously structural change has settled into journalism. If we consider the fundamental layers interconnected within the journalistic media ecologytechnology and social models of organization-what we discover is that the innovations which made journalism hybrid are now accepted features of core journalism. It has become difficult to imagine journalism without social media, without data, or journalism that is not also visual; at the same time, we have come to accept as the norm the role of bloggers and citizen journalists, and the changes that have shaken journalists. As regards the last 
layer of media ecology, discursive content, every actor currently involved in journalism is taking for granted aspects of journalism that were not previously considered.

This new reality, one in which technological, economic, labor changes have happened, has seeped through the cracks and eventually cemented itself into what is the journalism we experience today. As Witschge et al. (2019) explain, although journalism is characterized by change and complexity, it also presents "new states of stability and the rise of new structures".

We believe that in some way, hybrid practices have settled into norms and institutions, becoming implicit. This has happened despite the lack of a proper definition of this implicitness by those same actors who are enacting it (and the pundits who are observing them). Nowhere in the institutions of journalism all over the world is it said that journalists should be 'social media savvy' or that they should be 'social media famous'; nevertheless, newsrooms worldwide are asking their employers to integrate their work practices, and they are hiring professionals who have been trained specifically for the task. Or, even take it for granted. Journalists outside newsrooms do the same, even with more intensity. If practices exist, discursive content will follow, and vice versa.

Witschge et al. (2019) again highlights how 'hybrid' literature has provided an apt response to the inadequacy of the binary conceptualization of the field of journalism studies. Whereas certain dynamics used to be considered binary-us/them, journalist/citizen, and so on-adopting a 'hybrid' approach now adds "a 'both' option to the either/or dichotomy". However, Witschge rightly argues, this mindset does not truly overcome the binary framework because it still conceptualizes journalism as consisting of dualities.

Hybrid journalism is not just the kind of journalism that unites the dichotomy: it is the one that goes beyond the binary. The concept of 'going beyond' dichotomies-as opposed to the concept of unifying them-is already well present in the field; consider Witschge and Deuze's "Beyond Journalism" project. Deuze (2019) recognizes the messiness of what journalism is today and deems the attempt to categorize all of its complexity as a 'hybrid' too simple to function properly.

We state that (1) hybrid journalism is now the centre of the field; (2) The most established forms of hybrid journalism represent continuity rather than change; (3) The forms denoted as hybrid journalism bring homogeneity rather than dissimilarity. However, what does all this mean? What does it mean to say that journalism as a discursive institution finds its recomposition in hybridity? Its recomposition in the tale of 'merged' and 'networked' logics? It means firstly that the fact that hybrid journalism has become an integral and central part of the journalistic field does not mean that boundary-work has ended and that journalism will remain what it is now. Although hybrid journalism has achieved a central position, it could lose it. Secondly, and even more importantly, journalism, which has generally seen its autonomy eroded by two fundamental fields (politics and economics) (Bourdieu 1998), is now yielding degrees of autonomy to many others. However, the outcome of this process has yet to be understood to its full extent. Hybrid journalism, precisely in its essential characteristics, often proves more capable of pursuing what are recognized to be its most traditional values. Other times, it changes its appearance to such an extent that it is difficult to understand its purpose. Beyond the results, what appears certain is that journalism should no longer be considered for its autonomy, but for the weakness or strength restored by its ability to include, incorporate, and exchange with what just a decade ago would have been considered elements external to the journalistic field.

Funding: This work was supported by the Italian Ministry of Research and University under the PRIN research program ("National Projects of Relevant Interest", 2017) (grant number: 20175HFEB3).

Institutional Review Board Statement: Not applicable.

Informed Consent Statement: Not applicable.

Data Availability Statement: Not applicable.

Conflicts of Interest: The authors declare no conflict of interest. 


\section{References}

Altheide, David. 2013. Media Logic, Social Control, and Fear. Communication Theory 23. [CrossRef]

Altheide, David L., and Robert P. Snow. 1979. Media Logic. Thousand Oaks: Sage Publications.

Anderson, Christopher William, Emily Bell, and Clay Shirky. 2012. Post-Industrial Journalism: Adapting to the Present. New York: Tow Center for Digital Journalism.

Bailey, Ric. 2018. When Journalism and Satire Merge: The Implications for Impartiality, Engagement and "Post-Truth" Politics—A UK Perspective on the Serious Side of US TV Comedy. European Journal of Communication 33: 200-13. [CrossRef]

Barnard, Stephen R. 2016. "Tweet or Be Sacked": Twitter and the New Elements of Journalistic Practice. Journalism: Theory, Practice E Criticism 17: 190-207. [CrossRef]

Baym, Geoffrey. 2017. Journalism and the hybrid condition: Long-form television drama at the intersections of news and narrative. Journalism 18: 11-26. [CrossRef]

Borchardt, Alexandra. 2019. Get out of the Office and Talk to People. Nieman Lab (blog). 2019. Available online: https://www. niemanlab.org/2020/01/get-out-of-the-office-and-talk-to-people/ (accessed on 1 February 2021).

Bourdieu, Pierre. 1998. On Television. New York: The New Press.

Bowker, Geoffrey C., and Susan Leigh Star. 2000. Sorting Things out: Classification and Its Consequences. First Paperback Edition. Inside Technology. Cambridge and London: The MIT Press.

Broersma, Marce, and Jane Singer. 2020. Caught Between Innovation and Tradition: Young Journalists as Normative Change Agents in the Journalistic Field. Journalism Practice, 1-18. [CrossRef]

Carlson, Matt. 2016. Metajournalistic Discourse and the Meanings of Journalism: Definitional Control, Boundary Work, and Legitimation: Metajournalistic Discourse and the Meanings of Journalism. Communication Theory 26: 349-68. [CrossRef]

Carlson, Matt. 2017. Journalistic Authority: Legitimating News in the Digital Era. New York: Columbia University Press.

Carlson, Matt, and Seth C. Lewis, eds. 2015. Boundaries of Journalism: Professionalism, Practices and Participation. Explorations in Communication and History. London and New York: Routledge, Taylor \& Francis Group.

Chadwick, Andrew. 2013. The Hybrid Media System: Politics and Power. Oxford Studies in Digital Politics. Oxford and New York: Oxford University Press.

Cherubini, Federica, and Rasmus Kleis Nielsen. 2016. Editorial Analytics: How News Media Are Developing and Using Audience Data and Metrics. SSRN Electronic Journal. [CrossRef]

Compton, James R., and Paul Benedetti. 2010. Labour, New Media and the Institutional Restructuring of Journalism. Journalism Studies 11: 487-99. [CrossRef]

Delmastro, Marco, and Sergio Splendore. 2020. Google, Facebook and what else? Measuring the hybridity of Italian journalists by their use of sources. European Journal of Communication 17. [CrossRef]

Deuze, Mark. 2019. What Journalism Is (Not). Social Media + Society 5: 205630511985720. [CrossRef]

Deuze, Mark, and Tamara Witschge. 2020. Beyond Journalism. Hoboken: John Wiley \& Sons.

Edgerly, Stephanie, and Emily K. Vraga. 2019. News, Entertainment, or Both? Exploring Audience Perceptions of Media Genre in a Hybrid Media Environment. Journalism 20: 807-26. [CrossRef]

Eldridge, Scoot A., II, and Marcel Broersma. 2018. Encountering disruption: Adaptation, resistance and change. Journal of Applied Journalism \& Media Studies 7: 469-79. [CrossRef]

Erjavec, Karmen. 2004. Beyond Advertising and Journalism: Hybrid Promotional News Discourse. Discourse E Society 15: 553-78. [CrossRef]

Erjavec, Karmen. 2005. Hybrid Public Relations News Discourse. European Journal of Communication 20: 155-79. [CrossRef]

Gil de Zúñiga, Homero, Diehl Trevor, and Alberto Ardèvol-Abreu. 2018. When Citizens and Journalists Interact on Twitter. Journalism Studies 19: 227-246. [CrossRef]

Gillespie, Tarleton, Pablo J. Boczkowski, and Kirsten A. Foot, eds. 2014. Media Technologies: Essays on Communication, Materiality, and Society. Cambridge, MA, USA: The MIT Press.

Hanitzsch, Thomas, and Tim P. Vos. 2017. Journalistic Roles and the Struggle Over Institutional Identity: The Discursive Constitution of Journalism: Journalistic Roles and Institutional Identity. Communication Theory 27: 115-35. [CrossRef]

Harder, Raymond A., Steve Paulussen, and Peter Van Aelst. 2016. Making Sense of Twitter Buzz: The Cross-Media Construction of News Stories in Election Time. Digital Journalism 4: 933-43. [CrossRef]

Hermida, Alfred, and Mary Lynn Young. 2017. Finding the Data Unicorn: A Hierarchy of Hybridity in Data and Computational Journalism. Digital Journalism 5: 159-76. [CrossRef]

Hiippala, Tuomo. 2017. The Multimodality of Digital Longform Journalism. Digital Journalism 5: 420-42. [CrossRef]

Karpf, David. 2019. Something I No Longer Believe: Is Internet Time Slowing Down? Social Media + Society 5. [CrossRef]

Koliska, Michael, Kalyani Chadha, and Aliaon Burns. 2020. Talking Back: Journalists Defending Attacks against their Profession in the Trump Era. Journalism Studies, 1-18. [CrossRef]

Le Masurier, Megan. 2016. Slow Journalism: An introduction to a new research paradigm. Journalism Practice 10: 439-47. [CrossRef]

Lenhard, Johannes. 2020. Appadurai, Arjun and NetaAlexander. 2019. Failure. Cambridge: Polity Press. 120 pp. Hb.: £40.00. ISBN: 9781509504718. Social Anthropology 28: 527-28. [CrossRef]

Livingstone, Sonia. 2011. If Everything is Mediated, What is Distinctive About the Field of Communication? International Journal of Communication 5: 4. 
Mast, Jelle, Roel Coesemans, and Martina Temmerman. 2017. Hybridity and the News: Blending Genres and Interaction Patterns in New Forms of Journalism. Journalism: Theory, Practice E Criticism 18: 3-10. [CrossRef]

Nielsen, Rasmus Kleis. 2019. Vanguards and Rearguards in the Fight for the Future of Journalism. Rasmuskleisnielsen.Net (blog). 1 October 2019. Available online: https:/ / rasmuskleisnielsen.net/2019/10/01/vanguards-and-rearguards-in-the-fight-for-thefuture-of-journalism/ (accessed on 1 Febraury 2021).

Papacharissi, Zizi. 2015. Toward New Journalism(s): Affective News, Hybridity, and Liminal Spaces. Journalism Studies 16: 27-40. [CrossRef]

Paterson, Chris A., and David Domingo, eds. 2008. Making Online News. Bern: Peter Lang.

Peters, Chris, and Marcel Jeroen Broersma, eds. 2013. Rethinking Journalism: Trust and Participation in a Transformed News Landscape. Milton Park: Routledge.

Poell, Thomas, and Sudha Rajagopalan. 2015. Connecting Activists and Journalists: Twitter Communication in the Aftermath of the 2012 Delhi Rape. Journalism Studies 16: 719-33. [CrossRef]

Predictions for Journalism 2011. 2010. Nieman Lab (blog). 2010. Available online: https:/ /www.niemanlab.org/collection/predictions2011/\#all (accessed on 1 Febraury 2021).

Predictions for Journalism 2020. 2019. Nieman Lab (blog). 2019. Available online: https://www.niemanlab.org/collection/predictions2020/\#all (accessed on 1 Febraury 2021).

Robinson, Sue, and C. W. Anderson. 2020. Network Ethnography in Journalism Studies: A Mixed-Method Approach to Studying Media Ecologies. Journalism Studies 21: 984-1001. [CrossRef]

Ryfe, David. 2012. Can Journalism Survive? An Inside Look at American Newsrooms. Cambridge and Malden: Polity Press.

Scolari, Carlos A. 2012. Media ecology: Exploring the metaphor to expand the theory. Communication Theory 22: 204-25. [CrossRef]

Sehl, Annika, Cornia Alessio, Graves Lucas, and K. Nielsen Rasmuss. 2019. Newsroom Integration as an Organizational Challenge. Journalism Studies 20: 1238-59. [CrossRef]

Stross, Brian. 1999. The Hybrid Metaphor: From Biology to Culture. Journal of American Folklore 112: 254-67. [CrossRef]

Treré, Emiliano, and Alice Mattoni. 2016. Media Ecologies and Protest Movements: Main Perspectives and Key Lessons. Information, Communication \& Society 19: 290-306. [CrossRef]

Usher, Nikki. 2014. Making News at the New York Times. Ann Arbor: The University of Michigan Press.

Williams, Bruce Alan, and Michael X. Delli Carpini. 2011. After Broadcast News: Media Regimes, Democracy, and the New Information Environment. Communication, Society and Politics. New York: Cambridge University Press.

Witschge, Tamara, Cw Anderson, David Domingo, and Alfred Hermida. 2019. Dealing with the Mess (We Made): Unraveling Hybridity, Normativity, and Complexity in Journalism Studies. Journalism 20: 651-59. [CrossRef]

Zelizer, Barbie. 2019. Why Journsssalism Is About More Than Digital Technology. Digital Journalism 7: 343-50. [CrossRef] 